\title{
Concise clinical reviews
}

Published online: 20 November 2017

(C) International Osteoporosis Foundation and National Osteoporosis Foundation 2017

The Editors of Osteoporosis International recently announced a new initiative for the readership. An intermittent series of Concise Clinical Reviews will provide brief but informative updates on common issues with clinical relevance to practicing physicians and clinical investigators. The goal of each review is to provide an overview of an important clinical area with key references and tips to assist clinicians in managing patients with osteoporosis or metabolic bone disease. The National Osteoporosis Foundation designates this journalbased Continuing Medical Education (CME) activity for AMA PRA Category 1 Credit for residents of the USA. CME credit is offered for online completion of multiple questions associated with the article.

Authors are encouraged to submit proposed topics to the Review Editor of Osteoporosis International, E. Michael Lewiecki, at mlewiecki@gmail.com.
The first two Concise Clinical Reviews were published in 2017:

Roux C, Briot K (2017) Imminent fracture risk. Osteoporos Int 28(6): 1765-1769. https://doi.org/10.1007/s00198-017-3976-5

Visit https://cme.nof.org/Activity/5349400/Detail.aspx to complete the post-test for this article.

Watts N (2017) Adverse bone effects of medications used to treat non-skeletal disorders. Osteoporos Int 28 (10):27412746. https://doi.org/10.1007/s00198-017-4171-4

Visit https://cme.nof.org/Activity/5695864/Detail.aspx to complete the post-test for this article. 